University of Texas Rio Grande Valley

ScholarWorks @ UTRGV

$10-4-2020$

\title{
Telehealth Care and its Role in Undergraduate Medical Education in the COVID-19 era.
}

Peter J. Gonzalez

The University of Texas Rio Grande Valley, peter.gonzalez01@utrgv.edu

Dustin J. Paul

The University of Texas Rio Grande Valley

Follow this and additional works at: https://scholarworks.utrgv.edu/som9331

Part of the Medical Education Commons, Neurology Commons, and the Pediatrics Commons

\section{Recommended Citation}

Peter J. Gonzalez, Dustin J. Paul; Telehealth Care and its Role in Undergraduate Medical Education in the COVID-19 era.. Pediatrics March 2021; 147 (3_MeetingAbstract): 984-985. 10.1542/

peds.147.3MA10.984b

This Conference Proceeding is brought to you for free and open access by the School of Medicine at ScholarWorks @ UTRGV. It has been accepted for inclusion in MEDI 9331 Scholarly Activities Clinical Years by an authorized administrator of ScholarWorks @ UTRGV. For more information, please contact justin.white@utrgv.edu, william.flores01@utrgv.edu. 
Telehealth Care and its Role in Undergraduate Medical Education in the COVID-19 era.

Background

On March 17, 2020, the American Association of Medical Colleges issued a statement which "strongly supports medical schools pausing all student clinical rotations, effective immediately, until at least March 31." The University of Texas Rio Grande Valley School of Medicine immediately withdrew third- and fourth-year students from clinical rotation sites, and developed alternative, online-based clerkship curricula to complete for the remainder of the academic year. The COVID-19 pandemic has brought about many challenges to Undergraduate Medical Education, and has deprived upper-level students of foundational, in-person, clinical experiences. The UTRGV School of Medicine Department of Neurology is among the first programs in the country to offer an exclusively online, telehealth-focused, Pediatric Neurology Clerkship.

Methods

The UTRGV Pediatric Neurology clerkship curriculum was implemented between March 30-April 24, 2020. During this time, students were not allowed to work in-person at clinical sites, and the entire clerkship was conducted entirely online. Faculty and residents brought computers into the examination room, and students were able to take a patient history, present findings to the attending physician, and observe the physical examination using Zoom software and submit History \& Physical notes. Students also participated in Telehealth Care visits in which patients used Zoom to communicate with the clinic from home. Other responsibilities included simulated neurology cases, online didactic sessions, and readings from texts and clinical journals designed to prepare students for the National Board of Medical Examiners Clinical Neurology Subject Examination.

Results

Students interviewed 2-3 patients a day via Zoom. Technical difficulties over Zoom were common, which complicated history taking and viewing the physical examination for students and frustrated several patients. Given the low patient volume due to the COVID-19 pandemic, students were provided more time to prepare for the NBME Clinical Neurology Subject Examination and time to discuss cases and interpret radiographs with the attending physician. Students communicated with faculty daily over email, phone call, and text messaging, who provided immediate feedback and evaluation.

Conclusion

The COVID-19 pandemic brings unique challenges to Undergraduate Medical Education. While Telehealth Care visits do provide medical students with opportunities to develop interviewing, presentation, and documentation skills, exposure and familiarity with physical examination techniques remains limited. Audio, visual, and internet connectivity difficulties from patients, faculty, and students complicated many Telehealth Care visits. However, the low patient volume and close correspondence between students and faculty provided unique opportunities to discuss clinical cases in greater detail when compared to a traditional clinical clerkship. This alternative clerkship 
curriculum was created out of necessity to continue clinical medical education and is not intended to replace traditional clinical experiences. Further study may investigate how online clerkship curricula affect proficiency in physical examination skills, as well as student performance on NBME clinical examinations. 